\title{
CONTRADIÇÕES EM TORNO DA RELAÇÃO DO FÓRUM DO MACIÇO DO MORRO DA CRUZ COM O TERCEIRO SETOR: DESAFIOS POLÍTICOS E PEDAGÓGICOS*
}

\section{CONTRADICTIONS AROUND THE RELATION OF THE FÓRUM DO MACIÇO DO MORRO DA CRUZ WITH THE THIRD SECTOR: CHALLENGES AND EDUCATIONAL POLICY}

Jéferson Silveira Dantas**

Célia Regina Vendramini ${ }^{* * *}$

Resumo: O referido artigo tem por objetivo traçar, brevemente, a gênese do Fórum do Maciço do Morro da Cruz (FMMC), sua estrutura e suas respectivas comissões nos territórios dos morros de Florianópolis (SC) em sua área insular -, tendo como balizas: 1) a relação do FMCC com o Estado por meio de suas secretarias; 2) as parcerias do FMMC envolvendo organizações não governamentais (ONGs) e o aparato estatal. Em linhas gerais, procura abordar as complexas contradições em que se move o Fórum do Maciço ao buscar atender demandas históricas dos moradores dos morros relativas à segurança, escola, infraestrutura, trabalho e renda, por meio da organização coletiva, das políticas públicas estatais e das ações do terceiro setor. Além disso, reconhece-se aqui que boa parte destas demandas dos territórios dos morros está inscrita num processo histórico de intensa desigualdade social, que acaba por se refletir em processos de desigualdade de formação escolar para crianças e jovens residentes em tais territórios.

Palavras-chave: Fórum do Maciço do Morro da Cruz. Sociedade civil. Estado. Terceiro Setor. Desigualdade escolar. 
Abstract: The article aims to outline briefly the genesis of the "Fórum do Maciço do Morro da Cruz" (FMMC), its structure and its respective committees in the territories of the hills of Florianópolis (SC) - insular in your area - having as beacons: 1) FMMC's relationship with the State through its departments, 2) partnerships involving FMMC of nongovernmental organizations (ONGs) and the state apparatus. In general, seeks to address the complex contradictions that moves the FMMC meet historical demands of the residents of the hills on the safety, schools, infrastructure, employment and income through collective organizing, public policy and the state actions of third sector. Furthermore, it is recognized here that much these demands of the territories of the hills is entered in a historical process of intense social inequality, which ultimately reflect on processes of unequal schooling for children and adolescents in such territories.

Keywords: Fórum do Maciço do Morro da Cruz. Civil society. State. Third sector. Inequality school. 
A lição é clara: enquanto nós arquitetos rebeldes não conhecermos a coragem de nossa mente e estivermos preparados para darmos um mergulho igualmente especulativo em algum desconhecido, também nós continuaremos a ser objeto da geografia histórica (como abelhas operárias) em vez de sujeitos ativos que levem conscientemente ao limite as possibilidades humanas. Aquilo a que Marx deu o nome de 'movimento real' que vai abolir 'o estado de coisas atual' está sempre por ser feito e por ser apropriado. Esse é o único sentido que pode ter adquirido a coragem de nossa mente. (HARVEY, 2006, p. 334).

O Fórum do Maciço ${ }^{1}$ do Morro da Cruz (FMMC), organização de territórios dos morros da cidade de Florianópolis (SC), expressa a coragem a que David Harvey faz menção na epígrafe acima, ou o movimento real que, em meio a inúmeras contradições, visa combater a pobreza, a violência, o trabalho explorado ou a ausência dele, a falta de infraestrutura nos bairros da cidade (assistência à saúde, escolas, lazer, transporte, limpeza, fornecimento de água e energia, serviço de esgoto, entre outras). São muitas as questões que envolvem este complexo Fórum e suas Comissões (Educação, Meio Ambiente, Segurança, Trabalho e Renda, Comunicação), no que se refere à sua constituição, organicidade e atuação, à articulação entre as comissões, às suas lideranças, às suas reivindicações e atendimento ou não às demandas, à relação com as escolas e o poder público, apenas para citar algumas.

Neste artigo, elegemos uma questão polêmica que exige reflexão, especialmente porque nosso intento é contribuir para o avanço e fortalecimento do Fórum, como uma das possibilidades de organização, resistência e experiência coletiva dos sujeitos que vivem nos morros de Florianópolis. Nosso objetivo é analisar a forma como o FMMC e suas comissões foram estabelecendo relações com as instâncias estatais e com o terceiro setor. Desse modo, or- 
ganizamos o artigo em três tópicos. No primeiro, apresentamos a estrutura e o objetivo político central do FMMC (fórum ampliado); no segundo tópico, a constituição das comissões do FMMC e suas articulações; e, por fim, os limites do projeto político do FMMC e a sua relação com as instâncias estatais ${ }^{2}$ e com o terceiro setor.

\section{Antecedentes e estrutura do Fórum do Maciço do Morro da Cruz}

$\mathrm{O} \mathrm{FMMC}^{3}$ passou a se organizar de maneira mais efetiva entre 1999 e idos de 2000, tendo em vista as crescentes demandas estruturais dos territórios dos morros na cidade de Florianópolis. Entre os anos de 2002 e 2003 foi possível se ter uma visão mais ampla do FMMC a partir de um documento não datado da Comissão de Educação do Fórum (CE/FMMC) e intitulado Histórico da Comissão de Educação. Tal documento tinha por objetivo, justamente, traçar brevemente um marco inaugural do FMMC e de suas respectivas comissões. Neste documento, mais voltado às questões específicas da CE/FMMC, havia uma série de indagações sobre o seu processo identitário, a partir do seguinte roteiro: 1) O que é o FMMC? 2) Por que e como surgiu? 3) Quais os objetivos/anseios do FMMC em relação à CE/FMMC e vice-versa? Tais questões que, em princípio, poderiam parecer evidentes, demonstravam que ainda não havia uma compreensão geral do FMMC e, principalmente, quais eram os seus princípios ou intencionalidades políticas. A CE/ FMMC, segundo o documento citado anteriormente, não surgiu exatamente como comissão e sim como representação das escolas públicas que atendiam os territórios ${ }^{4}$ dos morros de Florianópolis, a partir de uma reunião de emergência convocada por um fórum interinstitucional que iniciou as primeiras discussões sobre políti- 
cas públicas para tais territórios. Este encontro teve por finalidade principal debater a problemática da violência e os seus efeitos nas escolas, notadamente em determinadas situações em que crianças e jovens do território 'Nova Descoberta' eram impedidas de chegarem à escola situada no território do 'Mont Serrat' (escola de educação básica Lúcia do Livramento Mayvorne). O mesmo ocorria com as crianças e jovens que estudavam nas áreas centrais de Florianópolis, impedidas de saírem de suas residências pelo 'toque de recolher' determinado pelo narcotráfico em inúmeras ocasiões (COMISSÃO DE EDUCAÇÃO, [s.d.]).

Não seria exagero, portanto, afirmarmos que a gênese do FMMC ocorreu em função da violência generalizada nos territórios dos morros. Segundo o ex-coordenador-geral do FMMC, Vilson Groh ([s.d.].) ${ }^{5}$,

[...] o Fórum do Maciço nasceu [durante] a conjuntura do governo Ângela Amin [1997-2000/2001-2004]. A gente vivia um momento de retração e o FMMC foi se constituindo em função da violência: violência nas escolas e violência nas comunidades (o tráfico estava extremamente forte neste período). Nas comunidades havia pouca força de atuação e então a gente foi buscando as pessoas e entrando em contato com diversos órgãos: Secretaria de Segurança, Polícia Rodoviária, Polícia Federal, Ministério Público e [demais] secretarias de Estado. Foi dali que foi nascendo este 'caldo do Fórum' e o FMMC foi ganhando um pouco de 'corpo', sistematizando o seu processo de ação. A Comissão de Educação nasce dentro deste processo de debate sobre a problemática do distanciamento das escolas com as realidades dos morros $^{6}$

Ainda que tal problemática tenha aparecido de forma mais evidente nas escolas, ela é expressão da condição de vida nos morros e tem raízes econômicas, particularmente na estrutura de classes sociais no modo de produção capitalista. Deve-se levar em con- 
sideração também, que a estrutura educacional oferecida para o público escolar dos morros é muito precária ${ }^{7}$, denotando uma formação escolar desigual em comparação a outras estruturas escolares, que atendem públicos com melhor nível de capital econômico.

No que se refere à estrutura do FMMC, ou o chamado fórum ampliado, este tinha por meta agrupar todas as comissões em projetos e ações comuns, visando uma organicidade do mesmo. No organograma que apresentamos a seguir (cf. Quadro 1), é possível observar a estrutura do Fórum. Na parte superior, visualizamos os grupos de trabalho (GTs) provenientes dos territórios dos morros. Eles não estão representados em sua totalidade, mas se referem a 18 territórios do maciço do Morro da Cruz. Além dos GTs, havia a previsão de uma assessoria técnica e científica que se responsabilizaria pela elaboração de proposições na área das políticas públicas, que pudesse levar em consideração o desenvolvimento sustentável dos territórios dos morros.

Quadro 1 - Organograma do Fórum do Maciço do Morro da Cruz

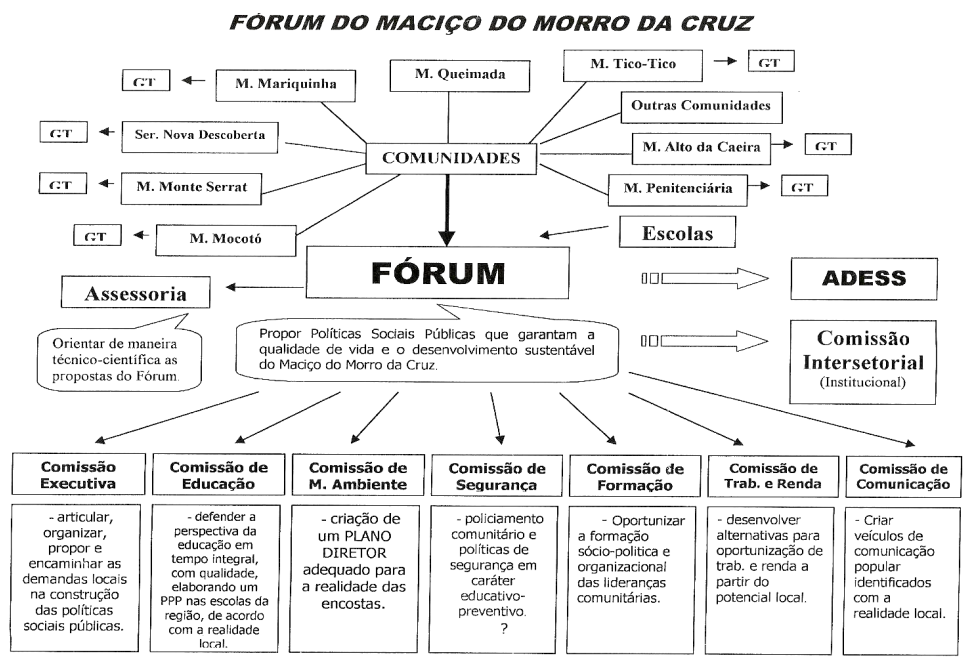

Fonte: Comissão de Educação ([s.d.]). 
O FMMC passou a ter uma sede física na área central de Florianópolis, localizada na Rua Visconde de Ouro Preto; esta sede se denominava Agência de Desenvolvimento Social Solidário (ADESS) e as reuniões ordinárias e extraordinárias da CE/FMMC em muitas ocasiões ocorreram neste espaço entre os anos de 2003 e 2004, especialmente. Dentre os seus principais objetivos estavam: a preservação e conservação do meio ambiente; ações voltadas à educação ambiental e ao processo de reflorestamento nas áreas degradadas do maciço do Morro da Cruz; assessoria jurídica gratuita aos moradores dos territórios dos morros e a implementação efetiva do Estatuto da Cidade; incentivo à experimentação não lucrativa de novos modelos socioprodutivos e de sistemas alternativos de produção, comércio, emprego e crédito; articulação da rede de economia solidária organizada e estratégias de desenvolvimento sustentável; estímulo à criação de escola em tempo integral, alfabetização de adultos, ensino supletivo e pré-vestibular, de forma a atender a demanda reprimida das áreas empobrecidas de Florianópolis; promoção da segurança alimentar e nutricional; estímulo à implementação de veículos de comunicação popular; assessoria de imprensa para os territórios dos morros; promoção de políticas de ações afirmativas e a organização popular a partir de seu caráter local, cultural e econômico.

Para o cumprimento de tantas demandas, a ADESS atuaria por meio da execução direta de projetos, pela doação e facilitação de recursos físicos, financeiros e humanos por parte do poder público e prestação de serviços a organizações sem fins lucrativos.

Já a comissão intersetorial, de caráter institucional, tinha por objetivo a segurança preventiva e a melhoria da qualidade de vida nas áreas empobrecidas de Florianópolis, reunindo em torno de si 
órgãos públicos estaduais e municipais, além das universidades (UFSC e UDESC, especialmente). Para o então secretário da Segurança Pública de Santa Catarina daquele período (2003), o deputado João Henrique Blasi, o trabalho da comissão intersetorial seria o primeiro passo para a adoção de políticas sociais públicas que proporcionasse melhores condições de vida nos territórios dos morros do maciço. Sobre a 'operação escorpião's da polícia militar - iniciada em março de 2003 e que objetivava o restabelecimento da ordem em função do 'poder paralelo' nos morros -, Blasi considerava que "passada a fase da repressão, dar-se-ia início aos trabalhos de inclusão social” (DA REDAÇÃO, 2003) ${ }^{9}$. Um destes trabalhos de inclusão seria o projeto 'escola aberta' ${ }^{10}$, que objetivava abrir as portas das escolas públicas nos finais de semana e feriados, como alternativa de lazer às crianças e adolescentes. As outras propostas vindas desta comissão intersetorial visavam à criação de espaços coletivos de lazer, além da geração de trabalho e renda a partir da concepção de uma escola de informática instalada no Mont Serrat. Vilson Groh chegou a afirmar que a comissão intersetorial seria o "encontro das possibilidades", algo que foi se revelando frágil do ponto de vista das políticas públicas nos anos posteriores. A comissão intersetorial ainda contava com o apoio das seguintes secretarias e órgãos públicos: Secretaria Regional da Grande Florianópolis (SDR), Secretaria da Saúde, Casa Civil, Secretaria de Estado da Educação e Inovação (SED), Prefeitura de Florianópolis, Federação Catarinense dos Municípios (FECAM), UFSC, UDESC, CASAN, CELESC, COHAB e Feesporte.

Na parte inferior do organograma (cf. Quadro 1) há a relação das comissões do FMMC e seus respectivos objetivos. Das sete comissões elencadas, podemos considerar que cinco delas estive- 
ram mais atuantes durante a trajetória de estruturação do FMMC: as comissões de Educação ${ }^{11}$, Meio Ambiente (CMA/FMMC), Segurança (CSEG/FMMC), Trabalho e Renda (CTR/FMMC) e, por fim, a de Comunicação (CCOM/FMMC). Estas comissões em determinados momentos conseguiram interagir em processos formacionais (tanto nas unidades de ensino quanto nos territórios dos morros), ainda que nem sempre de forma sistemática ou regular. Aliás, como veremos no subtítulo a seguir, muito das fragilidades orgânicas do FMMC correspondiam às descontinuidades dos trabalhos realizados por estas comissões, já que eram exercidas - excetuando-se a CE/FMMC - por educadores, pesquisadores e jornalistas voluntários, além de projetos de extensão provenientes, sobretudo, da UFSC, que também se mostraram descontínuos com o passar dos anos.

\section{Os objetivos políticos das comissões do Fórum do Maciço e a relação com as instâncias estatais}

Em princípio, todas as comissões do FMMC deveriam caminhar pari passu sem que houvesse precedência de qualquer comissão em relação à outra, já que se tratava de um projeto orgânico e, portanto, intimamente associado às melhorias das condições de vida dos/as moradores/as dos territórios do maciço do Morro da Cruz. Nesta direção, o próprio processo de formação em serviço das escolas associadas à Comissão de Educação e as suas ações comuns ${ }^{12}$ estavam imbricadas com as ações das comissões de Meio Ambiente, Segurança, Comunicação e Trabalho e Renda.

Segundo Nacur (2002), a temática da educação ambiental sempre foi um importante carro-chefe do FMMC, fortalecida pela asso- 
ciação com os departamentos de Geografia e Arquitetura da UFSC. Nesta articulação com as demais comissões, as unidades de ensino associadas à CE/FMMC passaram a definir as suas propostas pedagógicas de acordo com as suas prioridades e especificidades, $\mathrm{o}$ que originaria posteriormente os eixos temáticos da CE/FMMC, ou seja, temas gerais que estariam transversalizando os projetos políticos pedagógicos de cada unidade de ensino (DANTAS, 2007).

Com a definição das temáticas gerais estabelecidas por cada unidade de ensino, surgiram mais dois eixos: o sabor e saber (merenda sem agrotóxico ${ }^{13}$ e o eixo comunicação, sendo que este último tinha por objetivo - através da CCOM/FMMC - a elaboração de um jornal com todas as atividades desenvolvidas pelas comissões do FMMC. O jornal se tornou realidade e passou a se chamar Jornal Comunitário Guarapuvu ${ }^{14}$, sob a coordenação do jornalista Celso Vicenzi ${ }^{15}$. Além do jornal, algumas unidades de ensino da CE/FMMC (Lauro Müller e Padre Anchieta, notadamente), conseguiram implementar por um curto período a rádio-escola, onde os/as jovens destas escolas eram estimulados/as a produzirem programas de rádio por meio de uma formação específica.

Percebe-se, então, que as demais comissões gravitavam em torno da Comissão de Educação, tendo em vista que se tornava mais fácil articular os encontros de formação e mobilizações conjuntas através das unidades de ensino. É em tal contexto que surge a primeira parceria com o Centro Cultural Escrava Anastácia (CCEA), ONG coordenada por Vilson Groh, além do apoio da Associação dos Amigos da Casa da Criança e do Adolescente do Morro do Mocotó (ACAM) e do Centro de Educação e Evangelização Popular (CEDEP) por meio do projeto 'oficinas do saber'16. Ressalta-se aqui que, tanto a ACAM como o CEDEP, são coordenados por Groh. 
Em 2002 houve a primeira ação conjunta das comissões do FMMC denominada pacto das águas, comemorado no dia internacional das águas ( 22 de março) e tendo como principal problemática, justamente, a falta de recursos hídricos nos territórios do maciço. Tal ação passaria a fazer parte do cronograma conjunto das unidades de ensino da CE/FMMC.

A Comissão de Meio Ambiente neste período era extremamente atuante, reunindo-se regularmente para discutir o problema das encostas dos morros e sua consequente urbanização, evitando-se assim impactos ambientais nocivos. Contudo, tal projeto de extensão ficou restrito ao território do Mont Serrat, ainda que houvesse uma articulação mínima com os demais territórios do maciço do Morro da Cruz. Para o geógrafo Geraldo José Vieira (2002, p. 20) os maiores desafios da CMA/FMMC neste momento histórico, além do perigo de deslizamentos nas encostas, era o acúmulo de lixo produzido no território do Mont Serrat, já que o seu recolhimento ocorria até a altura da capela, ou seja, até a metade da encosta.

Não obstante, sabemos que a população dos territórios dos morros, apesar dos riscos iminentes de deslizamentos, não tem as garantias legais do poder público para a ocupação de outros espaços urbanos, o que faz com que tal problemática se torne uma "tragédia anunciada" a cada precipitação pluviométrica de grande intensidade na cidade de Florianópolis. Além disso, sabe-se que quase $70 \%$ da ocupação urbana em Florianópolis em sua área insular ocorreu em áreas de preservação permanente (dunas, mangues, encostas). O crescimento demográfico desordenado da capital catarinense e a ausência de infraestrutura (água, luz elétrica, saneamento etc.) nestas áreas de ocupação irregular, não recebem qualquer atenção do poder público. 
No que tangia à Comissão de Segurança, a mesma tinha por objetivo discutir um modelo de policiamento nos territórios dos morros de caráter preventivo, que não se restringisse à repressão, prática desencadeada, principalmente, no combate ao narcotráfico. Contudo, o secretário de segurança pública em 2003, João Henrique Blasi, não conseguiu cumprir a promessa de "inclusão social” gradativa e muito menos diminuir os efeitos de repressão policial. A “operação escorpião" tinha por meta coibir o tráfico de drogas, mas foi se mostrando ineficiente com o passar dos anos. A tão propalada polícia comunitária envolvendo o FMMC e a polícia militar, contava com apenas dois policiais militares para dar conta de todos os territórios do maciço ${ }^{17}$. A intensificação da repressão nos anos seguintes foi a resposta do poder público para os territórios dos morros do maciço ${ }^{18}$.

As articulações possíveis entre as comissões sempre foram muito difíceis, a tal ponto de nos dias de hoje termos apenas a CE/ FMMC como comissão atuante. Tais limites podem estar relacionados ao conjunto das opções políticas de suas lideranças. Para o ex-secretário-geral do Fórum do Maciço, Jair Batista:

As comissões de trabalho foram um período muito rico de experiência [sic] que deram muito certo, porém é um trabalho que exige muito esforço e dedicação, quase que exclusivo, e isso acaba sobrecarregando algumas pessoas que lideram o processo, porém como tudo é voluntário fica difícil sustentar a regularidade nos trabalhos. As ONGs fazem um trabalho muito importante e necessário nas comunidades de periferia, porém fazem parte do contraditório, na medida em que assumem as responsabilidades do poder público e este justifica sua omissão; ainda tem o lado da limitação no atendimento que não se estende a todas as comunidades e isso gera descontentamentos e dissidências $^{19}$. 
A atual secretária-executiva da $\mathrm{CE} / \mathrm{FMMC}^{20}$ compreende que a articulação das comissões atualmente é frágil ou praticamente inexistente. Todavia, recorda-se que no primeiro ano do mandato do prefeito Dário Berger em Florianópolis (2005-2008), houve uma intensa mobilização dos morros e de suas comissões, através de uma reunião estratégica na escola de educação básica Lauro Müller. Em contrapartida, a cooptação das lideranças do maciço através de agentes ligados ao poder público municipal devido às obras do PAC, também dispersou ou desmobilizou os pressupostos políticos estabelecidos pelo FMMC nos primeiros anos do governo Luiz Henrique da Silveira. Para a secretária da CE/FMMC:

Falar das outras comissões é complicado, porque a gente não vivenciou muito isso. O que eu vivenciei, o que eu senti, foi quando a gente conseguiu articular atividades conjuntas, que foi essa vez que a gente visitou o morro - todas as comissões - junto com a Rose Berger $^{21}$. Cada comunidade subia junto. Então, o pessoal se uniu para fazer alguma coisa. E a gente fazia oficinas nas escolas, e a história da rádio-escola vem em função da Comissão de Comunicação, que era uma das mais organizadas na época. A [Comissão de] Segurança também. A gente fez algumas ações. Por exemplo: alguém [de outra comissão] participava de uma reunião da CE/FMMC. Mas, assim, são destes momentos que eu me lembro dessa articulação maior. E, realmente hoje, nesta última reunião que eu participei no dia $1^{\circ}$ de março [de 2010], querendo retomar um pouco, estas comissões em princípio não esentadas. A única pessoa que falou em nome de uma comissão fui eu, falando como CE/FMMC. Os outros representantes eram das comunidades, mas nada como tinha antes, pessoas da universidade, que faziam parte da Comissão de Meio Ambiente. [...] Em nenhum momento eu vi isso sendo rearticulado na reunião de retomada do Fórum do Maciço. 
Em síntese, se levarmos em conta os objetivos gerais das comissões apresentados anteriormente no organograma do projeto político do Fórum do Maciço do Morro da Cruz (cf. Quadro 1), perceberemos também que tais intencionalidades, além de amplas, ainda não estavam totalmente nítidas. O objetivo geral da CE/FMMC se alicerçava na defesa da escola pública integral com qualidade, a partir da construção dos projetos políticos e pedagógicos de cada realidade escolar. Todavia, a defesa de tal perspectiva dependia também da aprovação orçamentária do poder público estadual em relação ao financiamento dos projetos elaborados por cada unidade de ensino. Isto significava/implicava a ampliação de concursos públicos para efetivação nos cargos de magistério e de supervisores/orientadores pedagógicos, e educadores com dedicação exclusiva em tais unidades de ensino, além de reparos infraestruturais nestas escolas. Tais pressupostos eram essenciais para a diminuição das diferenças escolares, tendo em vista que estas últimas são frutos de uma oferta desigual de escolarização por parte do poder público, que deliberadamente tem promovido toda a sorte de sucateamento destas escolas e em muitos casos desativando as mesmas.

Já a Comissão de Meio Ambiente defendia um plano diretor condizente com a realidade das encostas dos morros, algo que foi se mostrando pertinente até os dias de hoje. Em 2010 o plano diretor apresentado pela Prefeitura de Florianópolis - depois de quatro anos de discussão - não contemplou satisfatoriamente os territórios do maciço, muito menos outras localidades da capital catarinense. Aliás, as tentativas de encaminhamento do chamado 'plano diretor participativo' (PDP) à Câmara de Vereadores foram temporariamente suspensas por não atenderem as reivindicações 
dos núcleos distritais, além de não respeitarem o núcleo gestor constituído (SABOYA, 2010).

A Comissão de Segurança, que tinha por objetivo um policiamento comunitário e preventivo, viu ruir suas intencionalidades e, principalmente, o abandono de tal projeto ainda no primeiro mandato do governo Luiz Henrique da Silveira. A política de segurança continua sendo de caráter repressivo, desmobilizando qualquer tentativa de vínculo com os morros. Por seu turno, a Comissão de Comunicação conseguiu construir veículos de mídia popular durante algum tempo, mas devido ao caráter voluntário de seus participantes e a descontinuidade de suas ações, também se dispersou ao longo destes últimos anos. Talvez, de todas as comissões, a Comissão de Trabalho e Renda foi a que conseguiu delimitar e explanar melhor o seu objetivo político, tendo em vista a preocupação com o avanço da criminalidade que ceifava/ceifa a vida de centenas de jovens que se encontram fora do mercado formal de trabalho.

\section{Limites e avanços na constituição do Projeto Político do Fórum do Maciço}

A criação do FMMC significou um momento importante para o reconhecimento da luta e da resistência da sociedade civil organizada. Da articulação do FMMC foram se constituindo redes com projetos e 'parcerias' que criaram interfaces entre o público/popular, ressignificando esses espaços na construção de uma cultura de participação, solidariedade e cooperação (DACOREGIO; DANTAS, 2010). Todavia, tais projetos e parcerias estão muito atrelados 
ao terceiro setor através das ONGs. Sabe-se que, ainda que muitas ONGs sejam bem-intencionadas, elas fragilizam a sociedade civil e, sobretudo, as organizações políticas dos territórios dos morros, além de personalizarem lideranças (MONTAÑO, 2005).

Retomando a concepção restrita e ampliada de Estado, pode-se dizer que o objetivo político central do FMMC foi tentar romper com a simplificação da dualidade de poderes entre a sociedade política e a sociedade civil. No plano político,

\begin{abstract}
[...] na forma democrático-republicana do Estado capitalista moderno, puderam e podem coexistir (ainda que numa relação de integração/contradição) instituições liberais, oriundas das revoluções burguesas, com formas políticas democráticas, criadas pelas classes subalternas em seu processo de autodefesa, de luta contra os interesses das classes dominantes. [...], além da conquista do sufrágio universal (uma bandeira de luta da classe trabalhadora contra os pressupostos teóricos e práticos do liberalismo originário), a criação de organismos como sindicatos (proibidos pelos primeiros regimes liberais) e como os partidos políticos de massa (uma invenção das classes trabalhadoras), organismos que são hoje parte integrante da vida estatal de qualquer país capitalista desenvolvido. (COUTINHO, 1994, p. 41).
\end{abstract}

Assim, no âmbito da sociedade civil, as classes trabalhadoras por meio de aliados buscam exercer a sua "hegemonia", através da "direção" e do "consenso", contrapondo-se à sociedade política (Estado em sentido estrito nos termos gramscianos), afeita ao processo de dominação edificada na coerção (COUTINHO, 1994, p. 54). Contudo, se formos observar o objetivo central do FMMC ("propor políticas sociais públicas que garantam a qualidade de vida e o desenvolvimento sustentável do Maciço do Morro da Cruz"), perceberemos que a sua intencionalidade é o seu próprio 
limite, ou seja: como garantir que tal aposta possa ser respondida pelo Estado num contexto de enfraquecimento da sociedade civil por meio da prática do voluntariado ou de organizações não governamentais? O Estado burguês pode garantir a qualidade de vida dos territórios dos morros de Florianópolis? O que significa o 'desenvolvimento sustentável' em tais territórios?

Como bem assinala o professor Antonio Carlos S. Diegues (1992), o termo 'desenvolvimento sustentável' vem sendo utilizado de forma acrítica e ad nauseam, principalmente depois da realização da Eco-92 na cidade do Rio de Janeiro. Muito presente nos discursos governamentais e também de lideranças multilaterais (ONU, FMI, BIRD, UNESCO):

Este termo transita pelos mais diversos círculos e grupos sociais, desde as organizações não-governamentais até as de pesquisa, com notável e estranho consenso, como se fosse uma palavra mágica ou um fetiche. Uma análise mais aprofundada revela uma falta de consenso, não somente quanto ao adjetivo 'sustentável', como também ao desgastado conceito de 'desenvolvimento'. (DIEGUES, 1992, p. 22).

Deste modo, com a intensa crise dos chamados modelos 'desenvolvimentistas', o seu revisionismo atingiu a sua culminância com a possibilidade cada vez mais evidente da degradação do planeta e de seus recursos materiais, fazendo com que surgissem diversas ONGs que promovem a defesa ambiental ${ }^{22}$.

Contudo, no auge da discussão sobre o 'desenvolvimento sustentável', o Brasil ingressava na era dos regimes neoliberais, encetada com o governo Collor de Mello ${ }^{23}$ (1990-1992) e prolongada pelos governos Fernando Henrique Cardoso (1995-2002), Luiz Inácio Lula da Silva (2003-2010) e Dilma Rousseff (a partir 
de 2011). Logo, com a adoção do neoliberalismo em nosso país a partir da década de 1990 as mobilizações sociais foram fortemente fraturadas, principalmente através da estratégia da cooptação. Nos termos do ex-presidente Cardoso, a 'ação estatal' teria de dar lugar à 'ação pública', através do voluntariado e a racionalização dos gastos com saúde, educação e infraestrutura, tendo como palavras de ordem a 'flexibilização' e a 'adaptação funcional' da força de trabalho (DANTAS, 2009, p. 95).

Observamos que a intencionalidade política do FMMC estava acalcanhada numa escolha política que não radicalizava. Antes, porém, optava pelo regime de parcerias, voluntariado, desenvolvimento sustentável, economia solidária, redes sociais e a participação decisiva do chamado terceiro setor na mediação dos conflitos sociais. A Comissão de Trabalho e Renda, por exemplo, em conjunto com a Agência de Desenvolvimento Social e Sustentável, coordenada pelo professor Eriberto Meurer, apostou na economia solidária como fator de diminuição do empobrecimento dos morros, tendo como principal teórico o economista Paul Singer.

As ONGs realizam a mediação entre coletivos organizados e o poder de sistema governamental, assim como entre grupos privados e instituições governamentais (DANTAS, 2009, p. 301). Em outras palavras, o crescimento das ONGs desmobilizou os movimentos sociais, através de políticas de parceria implementadas pelo poder público. Isto revela também as orientações voltadas à desregulamentação do Estado na economia e na sociedade de forma geral, transferindo as responsabilidades estatais para os territórios dos morros ou fóruns organizados. Os movimentos populares perderam o apoio da Igreja Católica progressista (Teologia da Libertação) muito atuante nas décadas de 1970 e 1980. Ao rever suas doutrinas e práticas sociais, setores da Igreja Católica 
estariam alterando as diretrizes de suas ações no que se refere à participação popular na política do país (DANTAS, 2009, p. 314). Além disso, a denominada 'velha' militância política de esquerda estaria dando vazão à esquerda resignada e possibilista, nos termos de Carlos Montaño (2005).

Diante do desemprego estrutural e da precarização do trabalho formal, o Estado tem relegado suas funções/responsabilidades sociais ao domínio do privado, ou seja, às famílias, às instituições religiosas e filantrópicas, onde as mesmas responsabilizam-se por si numa 'rede de solidariedade' que possa proteger os mais pobres (SOARES, 2005, p. 12). Tal conjuntura pautada nas acepções políticas neoliberais permite e abriga com muita amplitude o chamado 'terceiro setor24, dominado por ONGs e mantidas, sobretudo, com recursos públicos.

Vilson Groh ([s.d.]), contudo, defende a participação das ONGs em contextos sociais empobrecidos, vendo nas mesmas mais 'possibilidades' do que 'limites':

Acho que depende como surgem as ONGs. Se tu olhas as nossas ONGs elas surgiram da base, as diretorias são da base até hoje. E continuarão sendo sempre da base. As ONGs podem ser instrumentos de processos. Agora, quando as ONGs são instrumentos de 'fora para dentro' destas realidades e as intervenções são deste caso, elas podem ser meramente captadoras de recursos e não desenvolver trabalhos relacionados ao processo. [...]. Eu vejo as ONGs dentro deste processo, porque as nossas organizações existiam antes de serem ONGs. Todas já possuem mais de vinte e cinco anos. O CEDEP nasceu em 1986 no continente e o CAPROM já vem desde 1982. [...]. As nossas organizações sempre ajudaram na formação dos moradores e na rediscussão política. E a gente sempre pegou no viés da educação popular. E com a visão também de que ONG um dia também tem de se acabar. $\mathrm{O}$ dia que tivermos um Estado com políticas públicas, do pon- 
to de vista de políticas estatais, acho que finda o papel da ONG. [...]. E aí a questão é: como é que tu constróis uma nova esfera política não-estatal de controle? [...]; qual é a relação entre o Estado e a sociedade civil neste processo todo da discussão? Não são instituições que se opõem, mas que podem trabalhar numa relação de composição com elementos da transgressão [grifos nossos]. E aqui o jeito de olhar a realidade e o jeito de olhar o papel do Estado, das políticas públicas e da intervenção da sociedade civil, passa pela capacidade de a gente dar um salto de qualidade e criar mecanismos de controle. [...]. Então, uma volta de foco de reflexão para mim hoje e de discutir a composição do Estado, é discutir mecanismos que se façam 'controle social', controle da gestão pública. [...]. Então, quando a gente discute o papel das ONGs e dos movimentos sociais, precisamos entender como é que saímos de um processo de radicalidade, de reivindicação e de reivindicação com proposição ${ }^{25}$.

Diante disso, o aclamado 'encontro das possibilidades' defendido por Groh no projeto político do FMMC estava alicerçado numa relação entre Estado e sociedade civil que, em princípio, não se opunha, mas que compunha diferentes formas de parceria, porém, com 'elementos de transgressão'. No final da década de 1990, ao defender a economia solidária como fator de diminuição da pobreza, Groh entendia que experiências concretas envolvendo o campo e a cidade eram capazes de fixar o homem na área rural e reduzir as elevadas taxas migratórias para as áreas periféricas da Grande Florianópolis. Historicamente, Groh procura situar o início do FMMC com suas primeiras 'parcerias':

O Fórum de Economia Solidária [FES] desenvolve duas experiências concretas na relação campo/cidade. A experiência da merenda escolar sem agrotóxico para 6.000 crianças e adolescentes (ensino fundamental e secundário). As crianças e adolescentes são de comunidades dos mor- 
ros que fazem parte da rede do maciço central, Fórum de Desenvolvimento Sustentável (são 6 escolas estaduais). E a experiência das cestas que é a venda direta do agricultor ao consumidor. O objetivo do fórum é aproximar associações e entidades que produzam no campo um produto ético e agroecológico, relacionando com as áreas empobrecidas (excluídas) da cidade para dar possibilidade a um comércio justo e solidário. No campo - as redes que gestaram o Fórum do Desenvolvimento dos Pequenos Municípios da encosta da Serra Geral. Dentro do fórum está a AGRECO (Associação de agricultores Ecológicos da Encosta da Serra Geral, na região da Grande Florianópolis). Esses fóruns têm a participação de professores da UFSC (Universidade Federal de Santa Catarina) que assessoram em suas áreas específicas, a partir das de cada [sic] realidade. Em 2001, o processo organizativo do Fórum começa a se fortalecer com a assessoria da Universidade Federal de Santa Catarina. A primeira reunião ocorreu no dia 12 de maio em Santa Rosa de Lima e desde então, os diversos atores e instituições dos municípios da região discutem e propõem políticas diferenciadas para estimular o desenvolvimento territorial. De maio a dezembro de 2001 o Fórum estabeleceu ações prioritárias para o desenvolvimento das encostas da Serra Geral, iniciando com a melhoria da qualidade de vida da energia e das estradas e com o projeto de telefonia. Também o saneamento básico e a educação passaram a receber mais atenção do poder público, e a merenda e o transporte escolar estão tendo prioridade nesta nova perspectiva. $\left(\mathrm{GROH},[\text { s.d.] })^{26}\right.$.

O Fórum de Economia Solidária nasceu, segundo Groh, em torno de 22 organizações de agricultores e consumidores do litoral catarinense, beneficiando seis mil crianças dos territórios do maciço do Morro da Cruz e 1,6 mil crianças da cidade de Criciúma ${ }^{27}$. Esta articulação entre campo e escola fez com que as unidades de ensino associadas à Comissão de Educação desenvolvessem eixos temáticos atentos à problemática rural e que, posteriormente, seriam incorporados aos seus respectivos Projetos Políticos Peda- 
gógicos (PPPs). Iniciavam-se ali as discussões sobre os recursos hídricos que a população de Florianópolis utiliza, procedentes de cinco rios das encostas da Serra Geral. Cada unidade de ensino da $\mathrm{CE} / \mathrm{FMMC}$ adotou um destes rios e, logo depois, foram realizados os primeiros estudos sobre o impacto ambiental nos territórios dos morros do maciço devido ao desmatamento indiscriminado e à ocupação humana desordenada.

Em linhas gerais, os desafios destes três fóruns citados por Groh (Fórum do Maciço, Fórum de Economia Solidária e Fórum de Desenvolvimento Sustentável), tinham por objetivo: 1) O consumo de alimentos de melhor qualidade; 2) incentivo à produção de alimentos saudáveis; 3 ) maior solidariedade entre o consumidor urbano e o trabalhador rural; 4) possibilidade do consumidor urbano conhecer melhor a vida e o trabalho do produtor rural; 5) apoiar o pequeno produtor rural; 6) superar a atual atomização do consumidor urbano e do produtor rural; 7) contribuir para o estabelecimento das relações éticas no trabalho; 8) evitar a degradação do meio ambiente; 9) contribuir para a criação de trabalho para a população da periferia da cidade; 10) realizar reuniões para analisar o tema 'alimentação e saúde', avaliando a qualidade dos produtos e o processo de entrega de cestas; 11) a curto e médio prazo, constituir uma associação de consumidores de produtos orgânicos. Para a consecução de tais demandas, Groh apontava que as articulações desses três fóruns iam se constituindo por meio de redes de projetos e parcerias, criando 'interfaces entre o público e o popular', o que este denominava de 'cultura da participação' Isto promoveria maior solidariedade e cooperação entre os 'excluídos das periferias' e os 'excluídos dos campos'.

Não sem razão, devido ao enorme potencial e poder de articulação de tal projeto envolvendo campo e cidade, uma ex-repre- 
sentante da Comissão de Educação do Fórum do Maciço chegou a afirmar que no período de gestação do projeto político do FMMC (1999-2002) vivia-se o 'auge' de sua estruturação. Em outras palavras, a questão da desigualdade social estava na 'pauta do dia' e isto precisava ser compreendido para 'além dos muros da escola', daí a necessidade de se articular o campo e a cidade, já que entendemos que tais espaços fazem parte de uma mesma totalidade histórica.

A economia popular solidária ${ }^{28}$ defendida por Groh não é algo recente e nem um fenômeno local. Segundo Tiriba e Picanço (2004), nas décadas de 1950 e 1960 observam-se iniciativas econômicas de setores populares, ainda que consideradas marginais ou fruto do "capitalismo periférico". Esta ganhou força e visibilidade no Brasil a partir de 2001 com a criação do grupo de trabalho brasileiro de economia solidária no interior do primeiro Fórum Social Mundial (FSM) na cidade de Porto Alegre (RS). Tal ideia foi encampada pelo governo Lula (2003-2010) como parte integrante das políticas institucionais do Ministério do Trabalho e do Emprego (MTE), por intermédio da Secretaria Nacional de Economia Solidária (SENAES) coordenada pelo economista Paul Israel Singer, “[...] principal teórico e defensor do fortalecimento do cooperativismo e demais empreendimentos de autogestão como resposta ao desemprego." (TIRIBA; PICANÇO, 2004, p. 23).

Para o mentor da economia solidária no Brasil, Paul Singer, deve-se ter claro que a economia solidária não é uma panaceia, mas um projeto organizativo socioeconômico que se opõe ao laissez-faire, onde a concorrência dá lugar à cooperação. Para este economista, o projeto cooperativo é antigo e foi concebido como alternativa proveniente do socialismo utópico ao capitalismo industrial.

Para termos uma ideia da relevância da economia solidária em nosso país, em 2005 havia praticamente 15 mil empreendimentos 
econômicos solidários no Brasil, atuando em 2.274 municípios brasileiros, o que correspondia a $41 \%$ das cidades que compõem o território nacional (WELLEN, 2008, p. 106). Neste sentido, Singer aposta na conjunção dos poderes públicos, sindicatos de trabalhadores, meio empresarial e organizações sociais (fóruns, movimentos populares) como força-motor no combate à lógica do capital, ou melhor, como um novo 'modo de produção' em que tais forças sociais pudessem encontrar um equilíbrio satisfatório sem superar o modo de produção capitalista. Assim, uma crítica central à economia solidária se refere ao

[...] fato de esse projeto preconizar o uso do capital como uma escolha individual. Para tanto, seus autores promovem uma visão mistificadora da atual fase do capitalismo, tratando as vontades humanas como independentes das determinações do capital. Esse recurso serve ideologicamente para justificar que o capital não representaria uma força ativa na totalidade social, mas que seria induzido de acordo com a subjetividade de cada um dos seus portadores. Com a vigência dessa pseudo-realidade, os representantes desse projeto apelam para a boa vontade das pessoas, para que essas façam um uso solidário do seu capital particular e ampliem, dessa forma, a 'economia solidária'. (WELLEN, 2008, p. 106).

Logo, a 'semente de uma nova produção', encorajada por Singer, teve sérios limites de continuidade no interior do projeto político do FMMC. A primeira razão foi a dificuldade de se manter a compra de hortifrutigranjeiros sem agrotóxicos produzidos pela AGRECO e que seriam consumidos pelos/as estudantes das unidades de ensino associadas à CE/FMMC e de outras escolas públicas interessadas em produtos saudáveis para a refeição de seus respectivos públicos escolares. O 'alto custo' alegado pelo poder 
público na compra de tais produtos foi um impeditivo significativo para a continuidade do projeto, denotando ainda o pouco compromisso da comissão intersetorial com os pressupostos políticos defendidos pelo FMMC. Acontece, porém, que efetivamente os produtos orgânicos sem agrotóxicos vendidos pela AGRECO eram muito mais caros que os vendidos nas feiras e supermercados das redondezas das unidades de ensino da CE/FMMC. Tratava-se de uma 'mercadoria diferenciada', sem a utilização de agrotóxicos e produzida por uma cooperativa de trabalhadores rurais. Mas, para manter a produtividade e a continuidade da cooperativa (com seus custos de produção), o produto final tinha elevado valor no mercado, e o Estado não estava disposto a pagar.

O grande limite da produção agroecológica é o cultivo em massa para atender o conjunto da população e não apenas setores sociais seletos que têm condições de adquirir um produto diferenciado. No caso específico em análise, os limites se ampliaram quando o principal comprador dos produtos da AGRECO (o Estado) terceirizou a merenda escolar da rede pública estadual, adquirindo produtos alimentícios de outros estados da federação e contribuindo decisivamente para o aumento da miséria na área rural de Santa Catarina.

Os limites e a fragilidade do projeto político do FMMC vão se evidenciando a partir da construção de seus modelos de parceria, muito mais voltados a uma resolução imediata de questões que são estruturais do que a uma 'ruptura' com a política estatal em vigor, via de regra repressora, ineficiente e apartada das reivindicações populares. De fato, as gestões neoliberais que se estruturam a partir da década de 1990 no Brasil procuraram fraturar os movimentos sociais e criminalizá-los a todo o custo. A racionalização com os gastos públicos nos setores sociais mais emergentes (saúde, educa- 
ção e infraestrutura) e, especialmente, oferecidos aos setores mais empobrecidos da sociedade, denotou a incapacidade do FMMC em compreender, historicamente, como estas alianças entre a sociedade política e a sociedade civil tinham 'prazo de validade'.

Nesta direção, ainda que as ONGs apresentem determinados níveis de eficiência, as mesmas esvaziam a participação mais ampla dos cidadãos em exigir políticas sociais estatais, criando uma cultura da 'autoculpa' e da 'autoajuda' ou 'ajuda mútua', desonerando o capital. A transferência de responsabilidades para os setores marginalizados da sociedade retira do Estado a universalização de seus encargos sociais permitindo que o terceiro setor ocupe esta mediação (MONTAÑO, 2005, p. 23).

No caso das ONGs coordenadas por Vilson Groh, algumas delas recebem recursos privados de outros países, como é o caso do Centro Cultural Escrava Anastácia (CCEA), mantida pelos irmãos maristas ${ }^{29}$, uma entidade religiosa que atua em 76 países com trabalhos focados na área educacional. Em dezembro de 2010 as ONGs coordenadas por Vilson Groh foram reunidas no Instituto Padre Vilson Groh, atingindo um universo de mais de nove mil crianças e jovens por meio de ações sociais e educacionais.

A 'filantropização da questão social', nos termos de Montaño, da qual o terceiro setor é seu porta-voz, não distinguiria mais o público do privado, muito menos a ideia/conceito entre Estado e governo. Nesta direção, para este autor, a parceria das ONGs com o Estado representaria mais do que implicações etimológicas. Assim, as parcerias com governos mais progressistas em nível estadual ou municipal se distinguiriam essencialmente daquelas realizadas com governos de viés neoliberal ou conservador (MONTAÑO, 2005, p. 137). O Fórum do Maciço do Morro da Cruz ao estabelecer parcerias com governos cunhadamente neoliberais 
tanto na esfera estadual como na municipal, perdeu força política e visibilidade social.

\section{Considerações finais}

Podemos inferir que os limites do projeto político do FMMC, em diferentes níveis, estavam concentrados na factibilidade do empenho das políticas públicas em resolver os problemas estruturais dos territórios dos morros de Florianópolis. A relação existente entre Estado, morros do maciço e suas respectivas lideranças, nesta direção, iam se forjando com muitas restrições, mas com algumas possibilidades, denotando também vivas contradições, que podem ser evidenciadas em três grandes aspectos: 1) $\mathrm{O}$ 'formato das lideranças'; 2) o regime ineficiente e/ou temporário das parcerias e 3) a desmobilização e o distanciamento crescentes entre a AGRECO e as comissões do FMMC.

No que tange ao primeiro aspecto, entendemos que as lideranças presentes no FMMC em sua gênese estavam intimamente associadas aos profissionais das universidades ou de sindicatos que, com o passar dos anos, foram se afastando por conta de outras atividades profissionais ou econômicas, denotando que a prática do voluntariado é extremamente danosa a determinado projeto político por conta de suas descontinuidades. É possível deduzirmos ainda que as lideranças dos territórios do maciço se encontravam representadas em tal projeto de uma maneira muito acanhada, para não dizer quase nula. Se não se formam lideranças em tais territórios, dificilmente haverá vínculo ou compromisso com algum projeto, além do processo de avaliação política se dar apenas 
em determinadas esferas, reduzindo processos democráticos e a horizontalidade do diálogo e dos debates. Lideranças personalizadas ou muito conciliadoras tendem a ser mais conservadoras, promovendo pouca pressão aos governos estaduais ou municipais.

Foi por meio do modelo de parcerias, que o projeto político do FMMC foi se desconfigurando. Como bem enfatizou Montaño (2005), as parcerias entre o público e o privado terceirizam as questões sociais e são adequadas para seus interesses em determinados contextos ou conjunturas sociais. No primeiro ano do governo Luiz Henrique da Silveira, acenava-se para as melhorias de condições de existência nos territórios dos morros, o que de fato mobilizou os sujeitos históricos partícipes do FMMC. Contudo, as mudanças no secretariado do governo catarinense, principalmente a partir de 2006, foram revelando uma postura política governamental cada vez mais apartada das questões sociais e mais aparelhada à criminalização dos movimentos sociais promovidos pelos/as trabalhadores/as.

$\mathrm{O}$ último aspecto tem a ver com a relação dos produtores rurais da AGRECO com as comissões do FMMC, principalmente no que tangia à compreensão histórica de se criar condições de trabalho adequadas aos pequenos proprietários rurais, evitando-se a migração e a degradação de suas condições de existência nas áreas periféricas da Grande Florianópolis. O projeto 'sabor e saber' (merenda sem agrotóxico) neste sentido foi extremamente importante, porém, a sua continuidade sofreu abalos, justamente, porque a 'parceria' com a instância governamental não foi atendida. Além disso, as unidades de ensino associadas à Comissão de Educação foram aos poucos perdendo o contato com os/as trabalhadores/as rurais, além do projeto 'sabor e saber' não fazer mais parte da realidade destas escolas. 
Ao mesmo tempo em que apontamos os limites do projeto político do FMMC, também reconhecemos as suas potencialidades. Milhares de crianças e jovens já foram beneficiadas com as intervenções sociais provenientes das ONGs coordenadas por Vilson Groh, principalmente aquelas que já haviam abandonado a escola e que se encontravam em total situação de vulnerabilidade social. Muitos jovens acessaram a universidade, com apoio de cursos pré-vestibular popular.

Nos últimos anos, entretanto, foi se tornando corrente a afirmação de que o Fórum do Maciço do Morro da Cruz e suas comissões haviam se extinguido, precisamente quando suas lideranças se dispersaram e as comissões, praticamente, deixaram de existir. Mais do que retomar o projeto político do FMMC seria necessário nos perguntarmos se o terceiro setor não estaria exercendo, hodiernamente, a função social almejada pelo FMMC desde a sua gênese. O fortalecimento das ONGs coordenadas por Groh teria obtido maiores êxitos sociais com o poder público e com as empresas privadas, sendo que estas últimas preocupam-se com a ideia de 'responsabilidade social' em seus processos de gestão e nos produtos que comercializam. Não nos cabe julgar e, sim, avaliar em que medida as ONGs teriam descaracterizado a perspectiva das lutas sociais nos territórios dos morros, iniciadas bem antes da organização do FMMC. Cabe-nos problematizar ainda o imenso desafio da Comissão de Educação, que iniciou a sua experiência política e pedagógica a partir de um fórum já estruturado, e que nos dias atuais tem procurado se 'reinventar' por meio da herança deixada pelo FMMC e de suas demais comissões. Isto pode significar uma reelaboração de tal experiência, promovendo novas associações de unidades de ensino e territorialidades envolvidas, assim como 
uma vinculação identitária que não estaria mais restrita aos morros do maciço. Mas, mais do que isso: um processo efetivamente democratizante nas escolas públicas, apartado do terceiro setor, vinculado às lutas do sindicato dos professores e com a emergência de novas lideranças tanto no magistério quanto nos territórios dos morros do maciço do Morro da Cruz.

Referências

ACIF - ASSOCIAÇÃO COMERCIAL E INDUSTRIAL DE FLORIANÓPOLIS. Contagem regressiva para a $4^{\text {a }}$ Benefest. 2010. Disponível em: <http://www.acif.org.br/noticias/view.php?cod=785>. Acesso em: 28 maio 2010.

BIELSCHOWSKI, Ricardo. Pensamento econômico brasileiro: o ciclo ideológico do desenvolvimento. 4. ed. Rio de Janeiro: Contraponto, 2000.

CENTRO CULTURAL ESCRAVA ANASTÁCIA. Incubadora popular de empreendimentos solidários. [s.d.]. Disponível em: <http://ccea. org.br/blog/?page_id=1797>. Acesso em: 21 ago. 2010.

COMISSÃO DE EDUCAÇÃO. FÓRUM DO MACIÇO DO MORRO DA CRUZ. Histórico da Comissão de Educação. Florianópolis, [s.d.].

CONDE, Fernando. Nota de pesquisa sobre o trabalho docente e a Educação do Campo. [s.d.]. Disponível em: <http://www. encontroobservatorio.unb.br/arquivos/artigos/172>. Acesso em: 28 ago. 2012.

COUTINHO, Carlos Nelson. Marxismo e política: a dualidade de poderes e outros ensaios. São Paulo: Cortez Editora, 1994.

DACOREGIO, Elisete Gesser Della Giustina; DANTAS, Jéferson. Espaço social, currículoescolar eformação docente: a experiência da Comissão de Educação do Fórum do Maciço do Morro da Cruz em Florianópolis/SC. In: I SEMINÁRIO INTERNACIONAL E III SEMINÁRIO NACIONAL: 
MOVIMENTOS SOCIAIS, PARTICIPAÇÃO E DEMOCRACIA, 2010, Florianópolis, Anais... Florianópolis: NPMS, 2010.

\section{DANTAS, Jéferson. Competências e habilidades e a formação docente} no contexto das Leis 5.692/1971 e 9.394/1996 em Santa Catarina. Rio de Janeiro: CBJE, 2009.

. Projeto histórico e construção curricular: a experiência social do Fórum do Maciço do Morro da Cruz. Revista Brasileira de Estudos Pedagógicos, Brasília, v. 88, n. 218, p. 122-139, jan./abr. 2007.

DA REDAÇÃO. Esperança para morador de morro: comissão busca reverter quadro de violência com ações sociais no Maciço do Morro da Cruz. 11 jun. 2003. Disponível em: <http://www1.an.com.br/2003/ jun/11/0ger.htm>. Acesso em: 12 maio 2010.

DIEGUES, Antonio Carlos S. Desenvolvimento sustentável ou sociedades sustentáveis: da crítica dos modelos aos novos paradigmas. São Paulo em Perspectiva, São Paulo, n. 6, p. 22-29, jan./jun. 1992.

GRAMSCI, Antonio. Maquiavel, a política e o Estado moderno. 7. ed. Tradução de Luiz Mário Gazzaneo. Rio de Janeiro: Civilização Brasileira, 1989.

GROH, Vilson. Os projetos locais de economia solidária no contexto atual: desafios e perspectivas. [s.d.]. Disponível em: $<$ http://protravessia. vilabol.uol.com.br/artigos_econ_soli.htm>. Acesso em: 14 maio 2010.

HARVEY, David. Espaços de esperança. Tradução de Adail Ubirajara Sobral e Maria Stela Gonçalves. 2. ed. São Paulo: Loyola, 2006.

INSTITUTO PADRE VILSON GROH. Disponível em: < http://ivg.net. br/blog/>. Acesso em: 23 ago. 2011.

MENEZES, Ana Cláudia. Operação escorpião: muita promessa e pouca solução. Jornal comunitário Guarapuvu, Florianópolis, p. 3, ago. 2003.

MÉSZÁROS, István. Para além do capital: rumo a uma teoria da transição. Tradução de Paulo César Castanheira e Sérgio Lessa. São Paulo: Boitempo; Editora da Unicamp, 2002. 
MONTAÑO, Carlos. Terceiro setor e questão social: crítica ao padrão emergente de intervenção social. 3. ed. São Paulo: Cortez, 2005.

NACUR, Eliete Schmitz Stang. A formação de educadores da Escola de Educação Básica Jurema Cavallazi a partir do Fórum do Maciço do Morro da Cruz. 2002. 47 f. Monografia (Especialização em Gestão Escolar) - Faculdade de Educação, Coordenadoria de Educação a Distância, Universidade do Estado de Santa Catarina, Florianópolis, 2002.

SABOYA, Renato. PDP Florianópolis: crônica de uma morte anunciada. 2010. Disponível em: <http://urbanidades.arq.br/2010/04/pdflorianopolis-cronica-de-uma-morte-anunciada/>. Acesso em: 26 jul. 2010.

SED - SECRETARIA DE ESTADO DA EDUCAÇÃO DE SANTA CATARINA. Escola aberta. [s.d.]. Disponível em: <http://www.sed. sc.gov.br/alunos/escola-aberta $>$. Acesso em: 29 jun. 2010.

SOARES, Laura Tavares. Prefácio. In: MONTAÑO, Carlos. Terceiro setor e questão social: crítica ao padrão emergente de intervenção social. 3. ed. São Paulo: Cortez, 2005. p. 11-13.

TIRIBA, Lia; PICANÇO, Iracy. O trabalho como princípio educativo no processo de produção de uma outra economia. In:

(Orgs.). Trabalho e educação: arquitetos, abelhas e outros tecelões da economia popular solidária. Aparecida, SP: Ideias e Letras, 2004. p. 22-29.

VARGAS, Diogo. Dever de proteger ou abuso de poder? Jornal A Notícia, Joinville, 8 set. 2007.

VIEIRA, Geraldo José. Mont Serrat: Maciço Central de Florianópolis (SC) - alguns aspectos geográficos. 2002. Relatório de Estágio (apresentado ao Departamento de Geociências da Universidade Federal de Santa Catarina) - Centro de Filosofia e Ciências Humanas, Universidade Federal de Santa Catarina, Florianópolis, 2002.

WELLEN, Henrique André Ramos. Contribuição à crítica da 'economia solidária. Revista Katálysis, Florianópolis, v. 11, n. 1, p. 105-115, jan./ jun. 2008. 


\section{Notas}

*Este artigo corresponde - de forma adaptada - ao segundo capítulo da tese de Doutorado intitulada "Espaços coletivos de esperança: a experiência política e pedagógica da Comissão de Educação do Fórum do Maciço do Morro da Cruz em Florianópolis/SC", de autoria do professor Jéferson Dantas, defendida em 2012 no Programa de Pós-Graduação em Educação da Universidade Federal de Santa Catarina.

${ }^{* *}$ Historiador, mestre e doutor em Educação pela Universidade Federal de Santa Catarina (UFSC). Articulador pedagógico na Comissão de Educação do Fórum do Maciço do Morro da Cruz (CE/FMMC). Membro e pesquisador do Núcleo de Estudos sobre as Transformações no Mundo do Trabalho (TMT). Professor temporário no Departamento de Estudos Especializados em Educação da UFSC. E-mail: <clioinsone@gmail.com>.

${ }^{*}$ Mestra e doutora em Educação pela Universidade Federal de São Carlos, com Pós-Doutorado pela Universidade de Lisboa. Atualmente é professora associada IV da Universidade Federal de Santa Catarina e membro do Grupo de pesquisa TMT - Núcleo de Estudos sobre as Transformações no Mundo do Trabalho. Pesquisadora Produtividade em Pesquisa do CNPq. E-mail: <celiavendram@ gmail.com>.

${ }^{1}$ Etimologicamente, o termo maciço corresponde ao recorte geomorfológico irregular no qual se concentra uma população plural em termos geográficos e sociais (econômicos, políticos e culturais) numa sucessão de mais de vinte territórios com identidades próprias (DANTAS, 2007).

${ }^{2}$ Deve ficar bem claro, porém, que Estado e governo não são sinônimos. Sempre que nos referirmos ao Estado neste artigo, estaremos aludindo à concepção de Estado político moderno, onde o Estado não "[...] se constitui como uma 'unidade orgânica', mas pelo contrário, foi imposto às 'classes subordinadas' a partir de relações de poder 'materiais' já prevalecentes da 'sociedade civil' no interesse preponderante (e não cuidadosamente 'equilibrado') do capital" (MÉSZÁROS, 2002, p. 581). Ou nos termos gramscianos, Estado e governo não são instâncias congruentes, pois tal “[...] identificação não passa de uma reapresentação da forma corporativo-econômica, isto é, da confusão entre sociedade civil e sociedade política." (GRAMSCI, 1989, p. 149).

${ }^{3}$ Através do FMMC foi possível estabelecer e manter projetos de extensão com os mais diversos cursos da Universidade Federal de Santa Catarina (UFSC), destacando-se: Serviço Social, Arquitetura, Biblioteconomia, Pedagogia e Geografia. Buscava-se, portanto, em tal contexto histórico, amparo técnico e logístico para a formulação de um plano diretor que atendesse às demandas dos territórios do maciço, bem como projetos que visassem à educação ambiental e à geração de renda (DANTAS, 2007).

${ }^{4}$ A categoria "território" tem sentido político problematizador em detrimento da expressão "comunidade", já que esta última tem clara conotação paternalassistencialista. Segundo Conde ([s.d.], p. 3-4), o conceito de território pode 
ser compreendido como um dos resultados da mediação entre a sociedade e suas frações de classe e a natureza: "Se num primeiro momento o território é resultado do processo de produção da vida humana pela transformação da natureza, processo em que o homem se apropria da natureza (superfície terrestre, solo, água, vegetação etc.) criando novas formas que permitem a socialização da natureza, em um segundo momento, o território se torna condição para que este processo se desenvolva como reprodução, como permanência e continuidade. As diferenciações e desigualdades que se produzem neste momento do processo de humanização da natureza não decorrem unilateralmente da área espacial, mas sim se tensionam na situação geográfica [...]. A consequência importante desta digressão é que o território pode ser pensado em dois momentos específicos da reprodução social: na sua gênese e no seu desenvolvimento."

${ }^{5}$ Vilson Groh (1954-) é padre e mestre em Educação pela UFSC. Reside no território do Mont Serrat desde a década de 1980 e desenvolve diversas atividades sociais por meio de ONGs nos territórios dos morros e periferias da Grande Florianópolis. Atualmente, tais ONGs foram reunidas no instituto que leva o seu nome, ou seja, o Instituto Vilson Groh.

${ }^{6}$ Entrevista concedida a Jéferson Dantas no dia 9 de janeiro de 2011.

${ }^{7}$ Precária no que se refere ao atendimento escolar, tendo em vista o elevado índice de rotatividade de professores; infraestrutura escolar comprometida; abandono estatal; e, notadamente, um projeto político pedagógico incapaz de articular a realidade social dos morros com práticas pedagógicas condizentes e, efetivamente, emancipadoras.

${ }^{8}$ A 'operação escorpião' foi uma operação conjunta das polícias militar e civil para coibir o tráfico de drogas e a violência nas áreas empobrecidas de Florianópolis. Todavia, os moradores dos territórios dos morros do maciço tinham a compreensão de que o tráfico de drogas era potencializado por pessoas que possuíam alto poder aquisitivo. Além disso, a ausência de áreas de lazer e o desemprego generalizado/estrutural contribuiriam para o fortalecimento do narcotráfico, segundo alguns moradores do Mont Serrat. Foi em tal contexto que se pensou pela primeira vez na criação de uma polícia comunitária no maciço do Morro da Cruz. O responsável pela coordenação estadual da polícia comunitária seria o coronel Jarí Luiz Dalbosco (MENEZES, 2003, p. 3).

${ }^{9}$ Estas informações foram retiradas da versão digital do jornal $A$ Notícia no dia 12 de maio de 2010. Contudo, a versão impressa desta matéria foi publicada no dia 11 de junho de 2003.

${ }^{10} \mathrm{De}$ acordo com as fontes oficiais (SED, [s.d.]), o projeto 'escola aberta' foi implantado em 2005, embora tenha sido elaborado em 2003, objetivando a superação do modelo tradicional de escola 'encerrada dentro dos seus próprios muros', com seus espaços e equipamentos ociosos nos finais de semana. Nesta direção, as escolas abririam as suas portas para atividades culturais, artísticas, esportivas, recreativas e de qualificação profissional, oferecendo à territorialidade local a sua infraestrutura e um conjunto de atividades 
organizadas e coordenadas, dentro de um projeto elaborado de forma participativa. A iniciativa de tal projeto tinha também apoio da UNESCO. Todavia, para a consecução de seus objetivos, o projeto escola aberta contava com profissionais voluntários e ONGs.

${ }^{11}$ A Comissão de Educação, inicialmente, possuía a seguinte nomenclatura: Comissão de Educação, Cultura e Lazer (NACUR, 2002).

${ }^{12}$ As ações comuns das unidades de ensino associadas à CE/FMMC são as seguintes: 1) Pacto das águas (que ocorre sempre no mês de março); 2) Mostra de educação ambiental no mês de junho, concernente à semana do meio ambiente e 3) Encontro de arte-educação. Tais ações contaram com a participação efetiva das comissões de meio ambiente e comunicação em diferentes estágios da organização do FMMC.

${ }^{13} \mathrm{O}$ projeto 'sabor e saber' teve início no ano de 2001 através da relação da CE/FMMC com a associação dos agricultores ecológicos das encostas da Serra Geral (AGRECO). Tal projeto foi encampado pelo poder público estadual na gestão de Esperidião Amin (1999-2002).

${ }^{14} \mathrm{O}$ jornal comunitário Guarapuvu teve vida curta, mas sua importância como instrumento popular de mídia foi bastante significativo. Todas as unidades de ensino associadas à CE/FMMC recebiam milhares de exemplares para serem distribuídos para estudantes e professores. O jornal contava com o apoio da Assembleia Legislativa de Santa Catarina, Sindicato dos Trabalhadores no Serviço Público Federal no estado de Santa Catarina (SINTRAFESC) e Universidade Federal de Santa Catarina (UFSC).

${ }^{15}$ Jornalista e assessor de imprensa da SINTRAFESC.

${ }^{16}$ O Centro de Educação e Evangelização Popular (CEDEP) é uma ONG que atende cerca de trezentas crianças e adolescentes de 6 a 15 anos, com gastos anuais em torno de $\mathrm{R} \$ 470$ mil. Parte destes recursos é utilizada na 'oficina do saber', onde os alunos participam de aulas de artes plásticas, teatro, música, dança, capoeira, basquete, informática e educação física. As oficinas são realizadas no contraturno do período escolar. Vilson Groh também está à frente de outras cinco ONGs há mais de 20 anos. O CEDEP é um dos mais antigos projetos coordenados por Groh, atendendo o território do Monte Cristo desde 1986. Há também o apoio de educadores italianos através do projeto Il Brasile è un aquilone ( $\mathrm{O}$ Brasil é uma pipa), a partir de intercâmbios e práticas pedagógicas. Os sindicatos dos bancários e dos eletricitários auxiliam com recursos para a manutenção de uma sala de administração e aquisição de materiais escolares (ACIF, 2010).

${ }^{17}$ Tais dados se referiam a 2010.

${ }^{18}$ Um exemplo da desproporcional e abusiva força da polícia militar ocorreu na madrugada do dia 26 de agosto de 2007, quando o estudante Lucas de Oliveira, 14 anos, da escola de educação básica Celso Ramos, associada à CE/FMMC, foi ferido com uma bala de borracha oriunda de uma espingarda calibre 12 quando voltava de uma festa na Beira-Mar Norte. Segundo Lucas, ele estava acompanhado de mais um amigo quando foi abordado pelos policiais militares, 
que faziam a ronda na entrada da Rua 13 de maio, que dá acesso ao morro do Mocotó. Depois de uma 'geral' (revista pessoal), os policiais teriam perguntado aos jovens se sabiam correr. Contaram até três e dispararam as balas de borracha. Os próprios policiais o socorreram, alegando que teriam visto Lucas com alguma arma. O outro jovem conseguiu escapar. O então comandante do $4^{\circ}$ batalhão da Polícia Militar, major Newton Ramlow, teria determinado a abertura de inquérito policial militar para apurar a denúncia de abuso de poder (VARGAS, 2007). Sob o comando de Ramlow foram frequentes as ações repressivas contra estudantes, principalmente no que se refere ao aumento das tarifas dos transportes coletivos na cidade de Florianópolis. No dia 31 de maio de 2010, tropas de choque invadiram a UDESC e agrediram estudantes, lembrando os momentos mais torpes do período ditatorial em nosso país. Além dos tradicionais cassetetes, spray de pimenta e balas de borracha, a Polícia Militar e a Polícia Civil utilizaram as armas 'taser', que emitem ondas de eletrochoque, causando paralisia momentânea. Estas armas já estão sendo alcunhadas de 'paus-de-arara portáteis'.

${ }^{19}$ Batista autorizou a divulgação de seu nome para este estudo e a entrevista foi concedida por meio de correio eletrônico no dia 18 de junho de 2010.

${ }^{20}$ Licenciada na área de Educação Física (Universidade Federal de Santa Maria), com especialização em Gestão e Educação Física Escolar. Encontra-se há mais de 20 anos no magistério e foi diretora-geral de uma escola associada à $\mathrm{CE} /$ FMMC (2003-2006). A entrevista foi concedida a Jéferson Dantas no dia 31 de março de 2010. Neste caso, foi preservada a identidade da depoente.

${ }^{21}$ Ex-secretária de Assistência Social e ex-cônjuge do prefeito Dário Berger.

${ }^{22}$ Em nosso país o ciclo desenvolvimentista anterior à década de 1970 (BIELSCHOWSKI, 2000), esteve calcado em três grandes correntes: a) setor público (não nacionalista); b) setor privado; e c) setor público (nacionalista). No primeiro caso, seus principais mentores - destacando-se Roberto Campos - defendiam um planejamento econômico com intensa participação do capital estrangeiro, através de uma comissão mista Brasil/EUA, omissa em relação à reforma agrária e à redistribuição de renda; no segundo caso, tendo como principal núcleo aglutinador a Confederação Nacional da Indústria (CNI) e a Federação das Indústrias de São Paulo (FIESP), seus pressupostos se alicerçavam na industrialização com proteção estatal ao capital industrial nacional, com a defesa do lucro (gerando má redistribuição da renda) e uma reforma agrária com sérios limites; e, por fim, no terceiro caso, tendo como principais articuladores o Banco Nacional de Desenvolvimento Econômico (BNDE), a Comissão Econômica para a América Latina e o Caribe (CEPAL) e o Instituto Superior de Estudos Brasileiros (ISEB), seus princípios se dirigiam para a industrialização planificada e fortemente apoiada por empreendimentos estatais, sendo favorável à distribuição de renda e à reforma agrária.

${ }^{23}$ Não terminou o seu mandato, pois sofreu processo de impeachment no ano de 1992, sob a acusação de corrupção passiva em relação aos mecanismos ímprobos de arrecadação de sua campanha. $\mathrm{O}$ mandato foi finalizado pelo 
seu vice, Itamar Franco, que nomeou como ministro da fazenda, Fernando Henrique Cardoso.

${ }^{24}$ Segundo Montaño (2005, p. 16-17), o denominado terceiro setor seria uma "mistificação de uma sociedade civil popular, homogênea e sem contradições de classe", opondo-se vigorosamente ao 'primeiro setor' (Estado) - supostamente burocrático e ineficiente - e ao 'segundo setor' (mercado), orientado pela procura do lucro.

${ }^{25}$ Entrevista concedida a Jéferson Dantas no dia 9 de janeiro de 2011.

${ }^{26}$ O referido texto foi retirado do sítio do 'Projeto Travessia' (http://protravessia. vilabol.uol.com.br/artigos_econ_soli.htm) e foi redigido em 2001.

${ }^{27}$ Município governado pelo Partido dos Trabalhadores (PT) naquela ocasião.

${ }^{28}$ A economia popular solidária defendida por Groh se fortaleceu alguns anos depois com a criação da Incubadora Popular de Empreendimentos Solidários (IPES). A partir da discussão sobre a inserção da juventude da periferia da Grande Florianópolis no mundo do trabalho, o Centro Cultural Escrava Anastácia em 2006 procurou viabilizar a Incubadora Popular de Cooperativas, para possibilitar o surgimento e o fortalecimento de iniciativas de geração de trabalho e renda, que tivessem como referência a economia solidária. Para tanto, procurou-se desenvolver oficinas de qualificação técnica e gerencial, articulando-as em redes que possibilitassem a otimização de recursos e redução de custos, apoiando-se na busca de parcerias, divulgando suas ações e acelerando a consolidação desses empreendimentos surgidos a partir de grupos sociais 'vulnerabilizados'. A IPES tem uma sede física num prédio de três andares, cedido pelo governo estadual, situado à Rua Tolentino Carvalho, n. 1, bairro Estreito, na área continental de Florianópolis. A IPES mantém suas atividades através de convênios com o Ministério do Trabalho e Emprego (MTE), na área de Arranjos Produtivos; com a Rede de Cooperação Berimbau, no âmbito da cooperação internacional - o MCE (Movimento di Cooperazione Educativa), a ASSUR (Associazione Scuola Università Ricerca), o Banco Monte dei Paschi e o Município de Roma (Comune di Roma XI) - com a Itália. Entre 2007 e 2008, o governo estadual, através do Fundo Social e da Secretaria de Estado do Desenvolvimento Regional da Grande Florianópolis (SDR), por meio de convênios e subvenções sociais, apoiou a continuidade de formação de distintas oficinas de capacitação profissional bem como empreendimentos cooperativos, que se encontra em fase de regulamentação e registro. A Secretaria Nacional de Economia Solidária (SENAES) ligada ao Ministério do Trabalho e Emprego do governo Lula também apoia esta ação, bem como o 'Instituto Lojas Renner.' Os 5 empreendimentos são os seguintes: cooperativa de confecção e moda jovem "Solto"; cooperativa de panificação e gastronomia "Sonho Nosso"; cooperativa de estética afro "Ellas"; cooperativa de soluções em informática "Universo Livre"; e cooperativa de papel reciclado "Eco Arte" (CENTRO CULTURAL ESCRAVA ANASTÁCIA, [s.d.]).

${ }^{29}$ A Congregação Marista recebeu do governo Colombo a escola de educação básica Lúcia do Livramento Mayvorne (localizada no território do Mont Serrat) 
no final de 2011, por um período de 10 anos. O poder público alegou que a escola estava com poucas matrículas e com problemas de gestão escolar. Este é um exemplo suficientemente grave de como o Estado tem se desresponsabilizado de suas ações sociais, permitindo de forma deliberada a privatização dos espaços educativos públicos em Santa Catarina. 